\title{
Changing Urbanization Patterns in US Lung Cancer Mortality, 1950-2007
}

\author{
Gopal K. Singh • Mohammad Siahpush • \\ Shanita D. Williams
}

Published online: 21 August 2011

(c) The Author(s) 2011. This article is published with open access at Springerlink.com

\begin{abstract}
This study examined disparities in lung cancer mortality rates among US men and women in metropolitan and non-metropolitan areas from 1950 through 2007. Annual age-adjusted mortality rates were calculated for men and women in metropolitan and non-metropolitan areas, and differences in mortality rates were tested for statistical significance. Log-linear regression was used to model annual rates of change in mortality over time, while Poisson regression was used to estimate relative risk after adjusting for age, sex, deprivation, and urbanization levels. Urbanization patterns in lung cancer mortality changed dramatically between 1950 and 2007. Compared to men in metropolitan areas, men aged 25-64 years in non-metropolitan areas had significantly lower lung cancer mortality rates from 1950 to 1977 and men aged $\geq 65$ years in nonmetropolitan areas had lower mortality rates from 1950 to 1985. Differentials began to reverse and widen by the mid1980s for men and by the mid-1990s for younger women. In 2007, compared to their metropolitan counterparts, men
\end{abstract}

G. K. Singh ( $\square)$

US Department of Health and Human Services, Health Resources and Services Administration, Maternal and Child Health Bureau, 5600 Fishers Lane, Room 18-41, Rockville, MD 20857, USA

e-mail: gsingh@hrsa.gov

\section{Siahpush}

Department of Health Promotion, Social and Behavioral Health, University of Nebraska Medical Center, Omaha,

NE 68198-4365, USA

e-mail: msiahpush@unmc.edu

\section{S. D. Williams}

National Institute on Minority Health and Health Disparities, National Institutes of Health, Bethesda, MD 20892, USA

e-mail: shanita@mail.nih.gov aged 25-64 and $\geq 65$ years in non-metropolitan areas had 49 and $19 \%$ higher lung cancer mortality and women aged $25-64$ and $\geq 65$ years in non-metropolitan areas had 32 and $4 \%$ higher lung cancer mortality, respectively. Although adjustment for deprivation levels reduced excess lung cancer mortality risk among those in non-metropolitan areas, significant rural-urban differences remained. Ruralurban patterns reversed because of faster and earlier reductions in lung cancer mortality among men and women in metropolitan areas. Temporal trends in rural-urban disparities in lung cancer mortality appear to be consistent with those in smoking.

Keywords Urbanization - Metropolitan .

Nonmetropolitan - Lung cancer mortality .

Deprivation $\cdot$ Age $\cdot$ Sex $\cdot$ Time trend

\section{Introduction}

Lung cancer is the leading cause of cancer death in the United States [1-3]. In 2007, 158,760 Americans died from lung cancer, which accounted for $28.2 \%$ of all cancer deaths and $6.6 \%$ of all US deaths [2]. US lung cancer mortality rates have risen dramatically in the past $6 \mathrm{dec}-$ ades, especially among women whose mortality rates increased from 5.9 deaths per 100,000 in 1950 to 40.0 in $2007[1,4]$.

Trends in lung cancer mortality are routinely analyzed according to age, sex, and race in the United States [2-4]. A few studies have also examined long-term trends in US lung cancer mortality according to socioeconomic status $[1,5]$. However, the extent to which disparities in lung cancer mortality rates between metropolitan and nonmetropolitan areas have changed over time has not been 
studied. Since the prevalence of smoking, a major determinant of lung cancer, varies substantially between rural and urban areas [6, 7], lung cancer mortality is also expected to vary by urbanization levels.

Examining temporal patterns is important because it allows us to track progress toward reducing social group disparities in lung cancer mortality, such as those between metropolitan and non-metropolitan areas [1,5]. Temporal analysis may also provide important insights into the differential impact of smoking prevention, cessation, and tobacco control programs among rural and urban populations since cigarette smoking is the most prominent cause of lung cancer, accounting for approximately $90 \%$ of all lung cancer deaths in the US [1].

In this study, we use a county-based rural-urban variable linked to national mortality data to examine the extent to which differences in lung cancer mortality among US men and women in metropolitan and non-metropolitan areas have changed during the past six decades. We also examine whether trends in rural-urban disparities in lung cancer mortality differ by age and sex. Additionally, we analyze rural-urban patterns in lung cancer mortality over time after adjusting for differences in socioeconomic deprivation levels.

\section{Methods}

To analyze rural-urban disparities in lung cancer mortality over time, we used the national vital statistics mortality database $[2,4,8]$. Since the national mortality database does not allow the direct computation of mortality rates for people in rural and urban areas, a county-based rural-urban continuum variable was linked to the annual age-sexcounty-specific mortality statistics from 1950 through 2007 [9-12]. The 1993 rural-urban continuum codes were used to analyze mortality data from 1950 to 1998 , whereas the 2003 rural-urban definition was used to compute mortality rates from 1999 to 2007 [9, 10, 12]. Each of the 3,141 counties in the mortality database was assigned one of the two metropolitan-nonmetropolitan categories.

The rural-urban continuum variable was first developed in 1993 and revised in 2003 by the US Department of Agriculture [9-12]. This variable classifies all US counties into 9 distinct urban-rural groups, based on the population size of the counties and their proximity to metropolitan areas [9-12]. For this study, we used two broad groups of metropolitan and non-metropolitan counties [12]. The metropolitan category includes large metro counties of a million people or more as well as smaller metropolitan counties of population $<250,000$. The non-metropolitan category includes small urban towns of population $<20,000$ as well as rural towns with a population of $<2,500$, which may or may not be adjacent to a metropolitan area [10, 12]. In 2007, there were 2,051 non-metropolitan and 1,090 metropolitan counties. The metropolitan and non-metropolitan areas accounted for 83 and $17 \%$ of the total US population in 2007, respectively [10, 12].

Age-sex-county-specific population estimates from 1950 to 2007, developed by the US Census Bureau, served as denominators for computing annual mortality rates $[2,4$, 13]. Between 1950 and 2007, an estimated 9,597,467 lung cancer deaths occurred in the US. Mortality rates for the metropolitan and non-metropolitan categories were ageadjusted by the direct method using the age composition of the 2000 US population as the standard and age-specific mortality rates for 19 age groups: $<1,1-4,5-9, \ldots, 80-84$, $85+$ years [1-3].

Annual age-adjusted lung cancer mortality rates were calculated for men and women of all ages and for those aged 25-64 and $\geq 65$ years in both metropolitan and nonmetropolitan areas. Age-specific analyses were conducted to identify differential patterns in mortality for the two broad age cohorts [1]. Log-linear regression models were used to estimate annual rates of change in mortality trends in metropolitan and non-metropolitan areas [14, 15]. By visually inspecting the trends in mortality rates for various socio-demographic groups, we identified successive segments of time within which log-linear models were fitted to estimate the magnitude of an increase or decrease in mortality. Specifically, within each time segment, the logarithm of the mortality rates were modeled as a linear function of time (calendar year), which yielded annual exponential rates of change in mortality rates $[14,15]$. Metropolitan-nonmetropolitan disparities in mortality were described by rate ratios or relative risks, which were tested for statistical significance at the 0.05 level $[1,5,12]$.

In order to examine whether lung cancer mortality differences between metropolitan and non-metropolitan areas can be explained by socioeconomic differences, we used a composite, area-based deprivation index that was linked to national mortality data at the county level. The deprivation index consisted of 11 census-based social indicators, which may be viewed as broadly representing material and social conditions and relative socioeconomic disadvantage in a given county [16]. Selected indicators of education, occupation, wealth, income distribution, unemployment rate, poverty rate, and housing quality were used to construct the index [16]. We linked the 1970 deprivation index to mortality data from 1950 to 1998 and the 2000 deprivation index to mortality data from 1999 to 2007. Substantive and methodological details of the US deprivation index are provided elsewhere [14, 16-18].

For each calendar year or time period between 1950 and 2007, we modeled lung cancer mortality as a function of age distribution, sex, deprivation quintiles, and 
metropolitan-nonmetropolitan residence. We used Poisson regression models, as estimated by the SAS GENMOD procedure, to estimate relative risks of lung cancer mortality among those in non-metropolitan areas compared to metropolitan residents after adjusting for deprivation levels [19].

\section{Results}

Urbanization patterns in lung cancer mortality changed dramatically between 1950 and 2007 (Figs. 1, 2). In 1950, the lung cancer mortality rate for persons living in nonmetropolitan areas was 10.7 deaths per 100,000 population, which was 33\% lower $(\mathrm{RR}=0.67 ; 95 \% \mathrm{CI}=0.64-0.69)$ than the rate of 16.1 for those in metropolitan areas. Although the differences in mortality narrowed over time, persons in non-metropolitan areas continued to have lower lung cancer mortality risks through the mid-1980s. However, by the early 1990s, differences began to reverse and widen, with those in non-metropolitan areas having significantly higher lung cancer mortality risks (Figs. 1, 2). In 2007, the age-adjusted lung cancer mortality rate for persons in non-metropolitan areas was 58.7 per 100,000 population, $20 \%$ higher than the rate of 48.7 for those in metropolitan areas $(\mathrm{RR}=1.20$; 95\% $\mathrm{CI}=0.19-0.22)$.

Temporal trends in lung cancer mortality in metropolitan and non-metropolitan areas differed by age and sex. Compared to men in metropolitan areas, men aged 25-64 in non-metropolitan areas had significantly lower lung cancer mortality rates from 1950 to 1977 and men aged $\geq 65$ in non-metropolitan areas had lower lung cancer mortality rates from 1950 to 1985 . Differentials reversed and started to widen by the mid-1980s for men and by the mid-1990s for younger women. In 2007, compared to their metropolitan counterparts, men aged $25-64$ and $\geq 65$ years in nonmetropolitan areas had $49 \%$ higher $(\mathrm{RR}=1.49$; 95\% $\mathrm{CI}=1.45-1.53)$ and $19 \%$ higher $(\mathrm{RR}=1.19 ; 95 \%$ $\mathrm{CI}=1.17-1.22$ ) lung cancer mortality, and women aged 25-64 and $\geq 65$ years in non-metropolitan areas had $32 \%$ higher $(\mathrm{RR}=1.32 ; 95 \% \mathrm{CI}=1.28-1.37)$ and $4 \%$ higher $(\mathrm{RR}=1.04 ; 95 \% \mathrm{CI}=1.02-1.06)$ lung cancer mortality, respectively.

During 1950-1980, lung cancer mortality among men aged 25-64 increased at $4.16 \%$ per year in non-metropolitan areas, significantly faster than the annual rate of increase of $2.53 \%$ in metropolitan areas (Table 1). Moreover, during 1981-2007, mortality fell at a more rapid pace for men aged 25-64 in metropolitan than in non-metropolitan areas, with the annual rates of decline in mortality being 3.12 and $1.69 \%$, respectively. Among women aged 25-64, lung cancer mortality in metropolitan and nonmetropolitan areas rose, respectively, by 5.6 and $5.9 \%$ annually during 1950-1990. However, while lung cancer mortality declined further by $2.24 \%$ annually during 1991-2007 for women in metropolitan areas, the mortality rate for women aged 25-64 in nonmetropolitan areas leveled off during the same period (Table 1; Fig. 1).

Lung cancer mortality among men aged $\geq 65$ years increased at a faster pace during 1950-1991 in nonmetropolitan areas than in metropolitan areas (Table 1). The decline in mortality among elderly men during 1991-2007 was also more pronounced in metropolitan than in non-metropolitan areas. Among women aged $\geq 65$ years, lung cancer mortality increased consistently throughout the 1950-2007 period at an annual rate of 4.9\% in metropolitan areas and at a rate of $5.1 \%$ in non-metropolitan areas (Table 1).

Temporal disparities in lung cancer mortality between metropolitan and non-metropolitan areas after adjusting for age, sex, socioeconomic deprivation are shown in Table 2 . Regardless of deprivation levels, persons in non-metropolitan areas had $33 \%$ lower risk of lung cancer mortality in 1950 than metropolitan residents. Differences in relative risk became smaller over time, and rural-urban patterns in mortality, after taking into account deprivation, reversed in 2003-2007, with those in non-metropolitan areas having a $5 \%$ higher risk of lung cancer mortality than those in metropolitan areas. In 2003-2007, adjustment for deprivation reduced higher mortality risk in non-metropolitan areas (relative to metropolitan areas) from 1.15 to 1.05 for the total population, from 1.23 to 1.05 for males, from 1.05 to 1.04 for females, from 1.35 to 1.11 for those aged 25-64 years, and from 1.08 to 1.03 for those aged $\geq 65$ years (data not shown).

\section{Discussion}

In this study, we examined long-term trends in metropolitan-nonmetropolitan disparities in US lung cancer mortality from 1950 through 2007. To our knowledge, this is first US study to systematically analyze temporal disparities in age- and sex-specific lung cancer mortality rates by urbanization level while taking into account differences in deprivation level.

The temporal analysis shows the dynamic nature of rural-urban disparities in US lung cancer mortality. In the 1950s, men and women in metropolitan areas had markedly higher lung cancer mortality rates than their non-metropolitan counterparts. Because of faster and earlier reductions in mortality among men and women in metropolitan areas, rural-urban patterns in lung cancer mortality reversed over time. In 2007, men and women in metropolitan areas had significantly lower lung cancer mortality rates than their non-metropolitan counterparts. Shifts in 
Fig. 1 Lung cancer mortality rates for US men and women in metropolitan and non-

metropolitan areas, 1950-2007

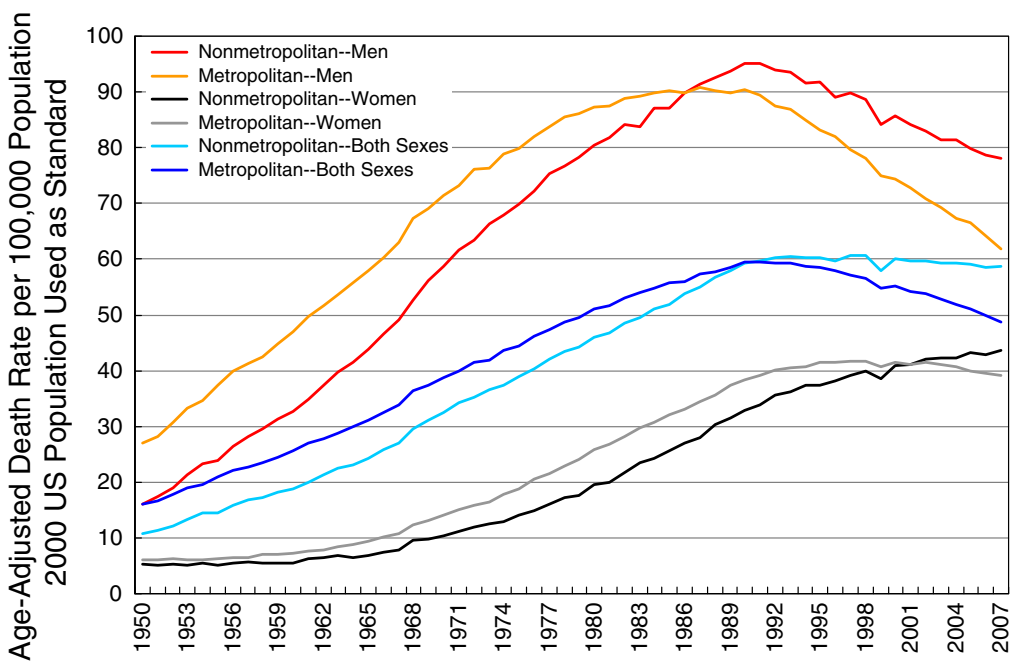

All Ages

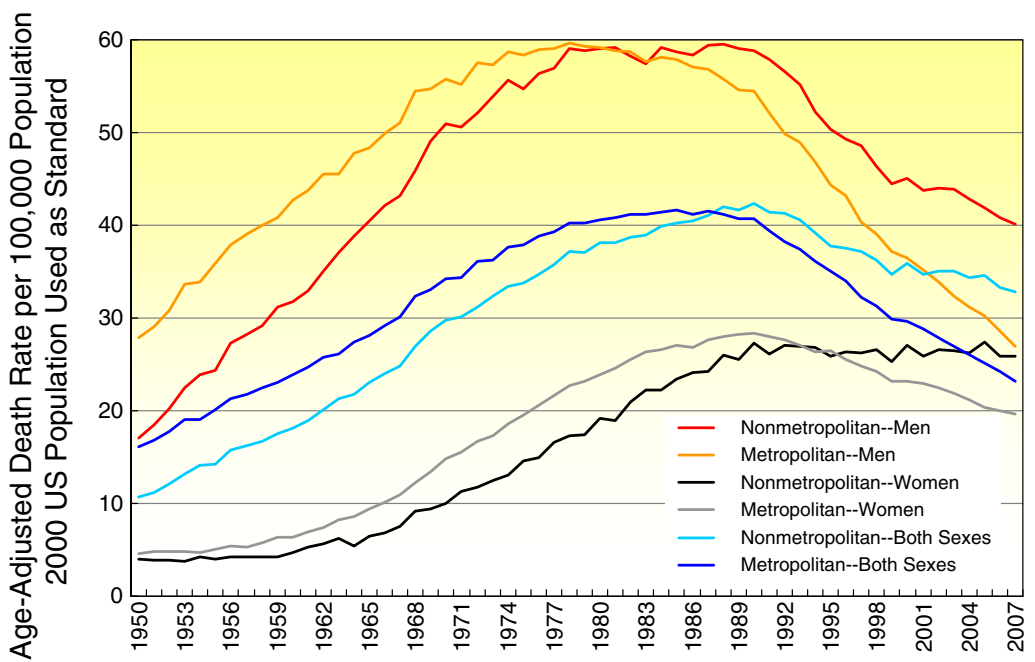

Ages 25-64

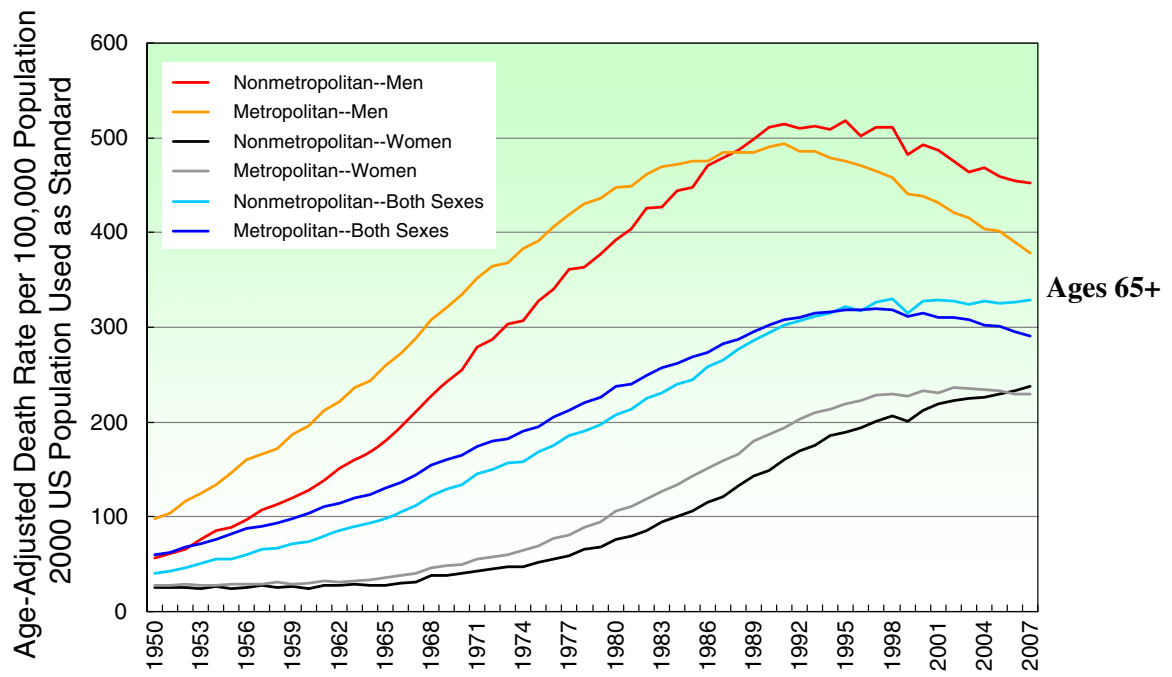

urbanization patterns in lung cancer mortality were more marked for men and women aged 25-64 than for those aged $\geq 65$ years. Although lung cancer mortality has increased at a much faster pace among women than among men in the past 6 decades [1, 4], it is important to emphasize that men in both metropolitan and non- 
Fig. 2 Age-adjusted relative risks of lung cancer mortality for US Men and Women in nonmetropolitan areas relative to those in metropolitan areas, 1950-2007

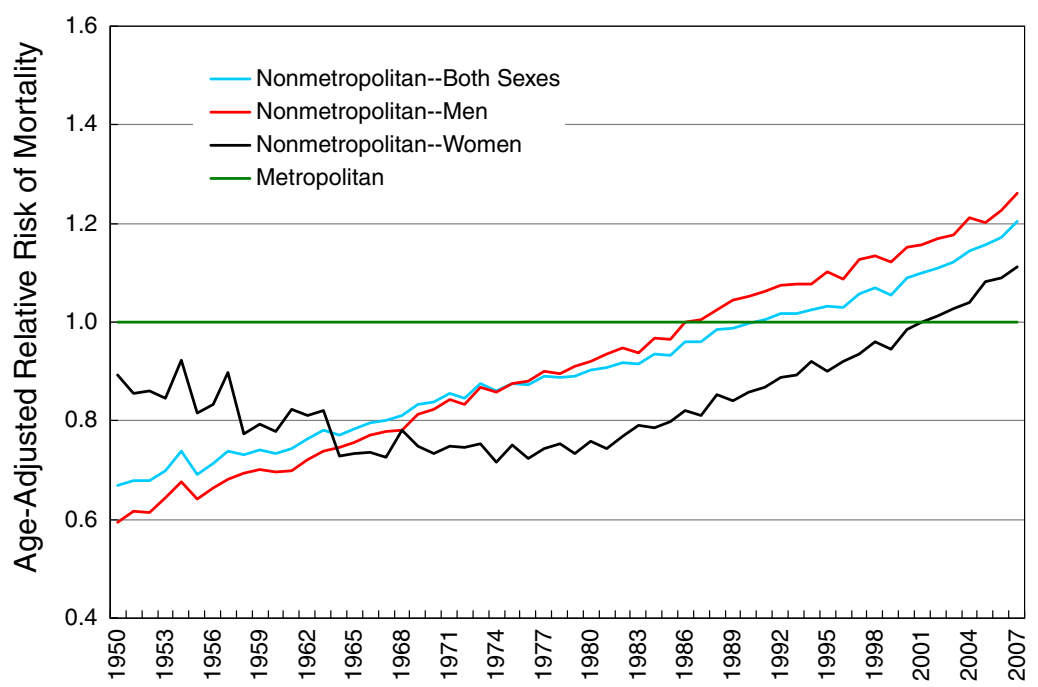

All Ages

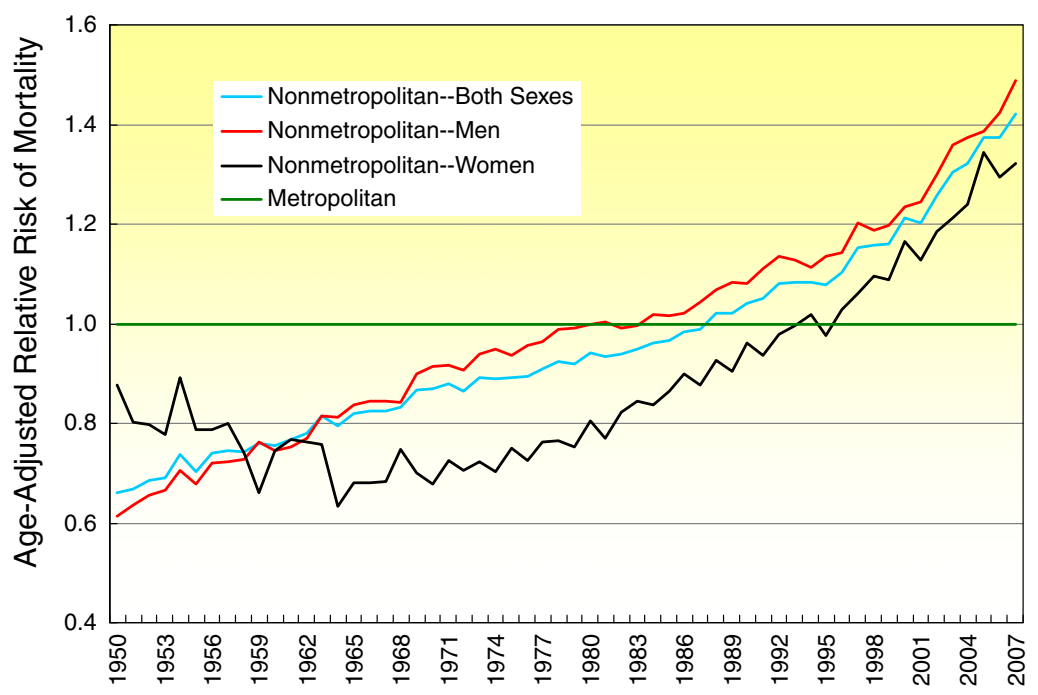

Ages 25-64

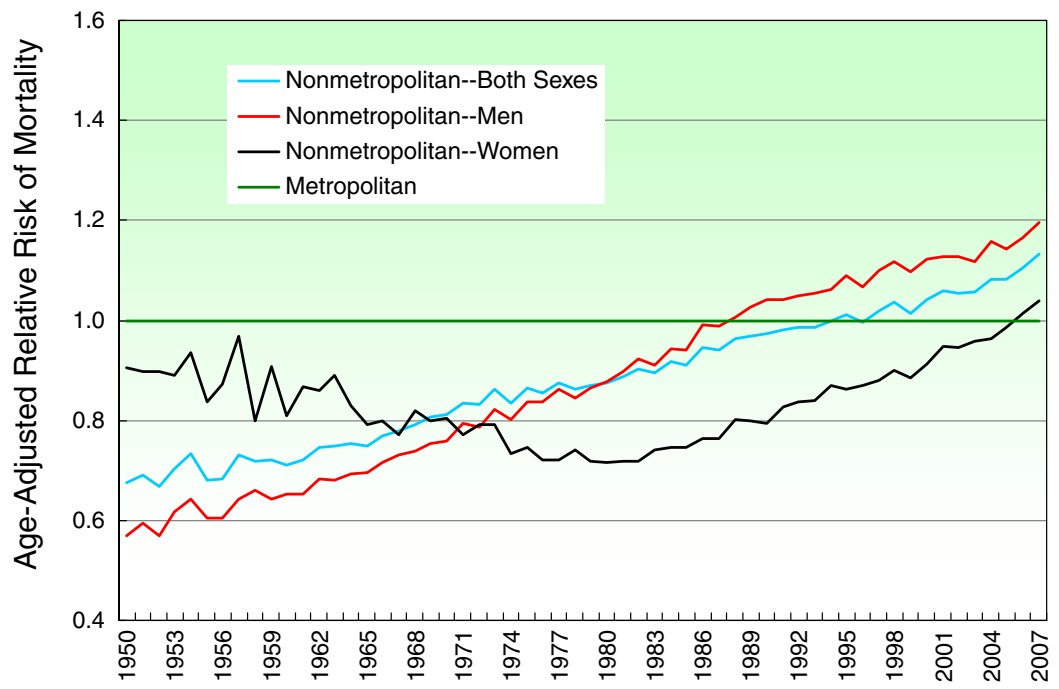

Ages 65+

Metropolitan and non-metropolitan areas of the US differ substantially in their socioeconomic characteristics $[10,12]$. The 2000 census data indicate higher poverty and 
Table 1 Average annual exponential rates of change (\%) for lung cancer mortality trends by age, sex, and metropolitan/non-metropolitan area, United States, 1950-2007

\begin{tabular}{|c|c|c|c|c|}
\hline & Time period & $\begin{array}{l}\text { Annual rate of change }(\%) \\
\text { and } 95 \% \text { confidence interval }\end{array}$ & Time period & $\begin{array}{l}\text { Annual rate of change }(\%) \\
\text { and } 95 \% \text { confidence interval }\end{array}$ \\
\hline \multicolumn{5}{|l|}{ Both sexes, all ages } \\
\hline Metropolitan area & 1950-1991 & $3.31(3.12-3.50)$ & 1992-2007 & $-1.29(-1.42$ to -1.17$)$ \\
\hline Non-metropolitan area & 1950-1991 & $4.31(4.10-4.52)$ & 1992-2007 & $-0.19(-0.30$ to -0.09$)$ \\
\hline \multicolumn{5}{|c|}{ Both sexes, age $25-64$ Years } \\
\hline Metropolitan area & $1950-1990$ & $2.46(2.23-2.70)$ & 1991-2007 & $-3.24(-3.33$ to -3.15$)$ \\
\hline Non-metropolitan area & $1950-1990$ & $3.53(3.26-3.79)$ & 1991-2007 & $-1.37(-1.58$ to -1.17$)$ \\
\hline \multicolumn{5}{|l|}{ Both sexes, age $65+$ years } \\
\hline Metropolitan area & 1950-2007 & $2.97(2.70-3.23)$ & & \\
\hline Non-metropolitan area & $1950-2007$ & $3.89(3.61-4.16)$ & & \\
\hline \multicolumn{5}{|l|}{ Men, all ages } \\
\hline Metropolitan area & $1950-1990$ & $3.06(2.75-3.36)$ & $1991-2007$ & $-2.25(-2.34$ to -2.15$)$ \\
\hline Non-metropolitan area & $1950-1990$ & $4.46(4.13-4.80)$ & 1991-2007 & $-1.26(-1.36$ to -1.17$)$ \\
\hline \multicolumn{5}{|l|}{ Men, age $25-64$ years } \\
\hline Metropolitan area & $1950-1980$ & $2.53(2.28-2.79)$ & $1981-2007$ & $-3.12^{\mathrm{a}}(-3.38$ to -2.85$)$ \\
\hline Non-metropolitan area & $1950-1980$ & $4.16(3.83-4.49)$ & $1981-2007$ & $-1.69(-1.91$ to -1.48$)$ \\
\hline \multicolumn{5}{|l|}{ Men, age $65+$ years } \\
\hline Metropolitan area & $1950-1991$ & $3.99(3.62-4.35)$ & $1992-2007$ & $-1.68(-1.81$ to -1.56$)$ \\
\hline Non-metropolitan area & $1950-1991$ & $5.53(5.17-5.89)$ & 1992-2007 & $-0.94(-1.12$ to -0.77$)$ \\
\hline \multicolumn{5}{|l|}{ Women, all ages } \\
\hline Metropolitan area & $1950-2002$ & $4.75(4.47-5.02)$ & 2003-2007 & $-1.24(-1.40$ to -1.08$)$ \\
\hline Non-metropolitan area & 1950-2002 & $5.03(4.80-5.26)$ & 2003-2007 & $0.79(0.29$ to 1.28$)$ \\
\hline \multicolumn{5}{|l|}{ Women, age 25-64 years } \\
\hline Metropolitan area & $1950-1990$ & $5.62(5.27-5.96)$ & 1991-2007 & $-2.24(-2.36$ to -2.13$)$ \\
\hline Non-metropolitan area & $1950-1990$ & $5.93^{\mathrm{b}}(5.63-6.23)$ & $1991-2007$ & $-0.07(-0.27$ to 0.14$)$ \\
\hline \multicolumn{5}{|l|}{ Women, age $65+$ years } \\
\hline Metropolitan area & 1950-2007 & $4.93(4.66-5.21)$ & & \\
\hline Non-metropolitan area & 1950-2007 & $5.06(4.80-5.31)$ & & \\
\hline
\end{tabular}

Log-linear regression models were used to estimate annual rates of change for each demographic group within each time segment

a The lung cancer mortality rate for men aged 25-64 in metropolitan areas decreased on average by 3.12\% per year during 1981-2007

b The lung cancer mortality rate for women aged 25-64 in non-metropolitan areas increased on average by 5.93\% per year during 1950-1990

unemployment rates and lower median family incomes in non-metropolitan areas compared to metropolitan areas $[10,12]$. However, as shown in Table 2, socioeconomic differences only partly account for the rural-urban differences in lung cancer mortality. Significant differences in lung cancer mortality remained even after the deprivation adjustment. For example, for the most recent period 2003-2007, although rural residents within the most affluent area group did not differ from their urban counterparts in their lung cancer mortality rates, rural residents did have significantly higher mortality rates in more deprived groups compared to urban residents. Within the most deprived area group, the age-adjusted lung cancer mortality rate in non-metropolitan areas during 2003-2007 was 66.7 per 100,000 population, $47 \%$ higher than the rate of 45.3 in metropolitan areas (data not shown).
Trends in rural-urban disparities appear to follow the course of temporal socioeconomic disparities in lung cancer mortality, which, as shown here and elsewhere, underwent a reversal and widening of the socioeconomic gradient between 1950 and 2007, with those in more deprived groups currently showing significantly higher mortality risks $[1,5]$. The reversal and subsequent widening of metropolitan-nonmetropolitan disparities in lung cancer mortality since the 1980s may reflect changing rural-urban patterns in smoking behaviors over the longterm [1]. Unfortunately, rural-urban patterns in smoking prevalence are not available prior to 1976. According to our analysis of the 1976 National Health Interview Survey (NHIS) data, higher smoking rates were found among persons living in metropolitan and more urbanized areas [20]. In 1976, the current smoking prevalence among 
Table 2 Adjusted relative risks (RR) of lung cancer mortality derived from Poisson regression models according to metropolitan-nonmetropolitan residence and socioeconomic deprivation quintiles, United States, 1950-2007

\begin{tabular}{|c|c|c|c|c|c|c|c|c|c|c|c|c|c|}
\hline \multirow{3}{*}{$\begin{array}{l}\text { Year } \\
1950\end{array}$} & \multicolumn{3}{|c|}{$\begin{array}{l}\text { Nonmetropolitan versus } \\
\text { metropolitan area }\end{array}$} & \multicolumn{3}{|c|}{$\begin{array}{l}\text { Most deprived versus } \\
\text { least deprived group }\end{array}$} & \multirow[t]{3}{*}{ Year } & \multicolumn{3}{|c|}{$\begin{array}{l}\text { Nonmetropolitan versus } \\
\text { metropolitan area }\end{array}$} & \multicolumn{3}{|c|}{$\begin{array}{l}\text { Most deprived versus } \\
\text { least deprived group }\end{array}$} \\
\hline & \multirow{2}{*}{$\frac{\mathrm{RR}}{0.67}$} & \multicolumn{2}{|c|}{$95 \% \mathrm{CI}$} & \multirow{2}{*}{$\frac{\mathrm{RR}}{0.80}$} & \multicolumn{2}{|c|}{$95 \% \mathrm{CI}$} & & \multirow[t]{2}{*}{$\mathrm{RR}$} & \multicolumn{2}{|c|}{$95 \% \mathrm{CI}$} & \multirow[t]{2}{*}{$\mathrm{RR}$} & \multicolumn{2}{|c|}{$95 \% \mathrm{CI}$} \\
\hline & & 0.64 & 0.70 & & 0.73 & 0.87 & & & & & & & \\
\hline 1951 & 0.68 & 0.66 & 0.71 & 0.83 & 0.76 & 0.89 & 1976 & 0.83 & 0.82 & 0.85 & 1.04 & 1.01 & 1.08 \\
\hline 1952 & 0.68 & 0.65 & 0.71 & 0.77 & 0.71 & 0.83 & 1977 & 0.84 & 0.83 & 0.86 & 1.09 & 1.05 & 1.13 \\
\hline 1953 & 0.70 & 0.67 & 0.73 & 0.84 & 0.78 & 0.90 & 1978 & 0.84 & 0.83 & 0.86 & 1.09 & 1.06 & 1.13 \\
\hline 1954 & 0.72 & 0.69 & 0.74 & 0.88 & 0.83 & 0.95 & 1979 & 0.85 & 0.83 & 0.86 & 1.09 & 1.06 & 1.13 \\
\hline 1955 & 0.70 & 0.67 & 0.72 & 0.85 & 0.79 & 0.91 & 1980 & 0.86 & 0.85 & 0.88 & 1.07 & 1.04 & 1.11 \\
\hline 1956 & 0.70 & 0.68 & 0.73 & 0.90 & 0.84 & 0.96 & 1981 & 0.85 & 0.84 & 0.87 & 1.14 & 1.10 & 1.17 \\
\hline 1957 & 0.73 & 0.70 & 0.75 & 0.86 & 0.81 & 0.92 & 1982 & 0.86 & 0.85 & 0.88 & 1.14 & 1.11 & 1.17 \\
\hline 1958 & 0.73 & 0.71 & 0.75 & 0.85 & 0.80 & 0.91 & 1983 & 0.87 & 0.86 & 0.88 & 1.10 & 1.07 & 1.14 \\
\hline 1959 & 0.72 & 0.70 & 0.74 & 0.93 & 0.88 & 0.99 & 1984 & 0.88 & 0.87 & 0.90 & 1.13 & 1.10 & 1.17 \\
\hline 1960 & 0.72 & 0.70 & 0.74 & 0.93 & 0.88 & 0.98 & 1985 & 0.89 & 0.87 & 0.90 & 1.12 & 1.08 & 1.15 \\
\hline 1961 & 0.72 & 0.70 & 0.74 & 0.95 & 0.90 & 1.00 & 1986 & 0.90 & 0.89 & 0.92 & 1.14 & 1.11 & 1.17 \\
\hline 1962 & 0.74 & 0.72 & 0.76 & 0.97 & 0.92 & 1.02 & 1987 & 0.89 & 0.88 & 0.90 & 1.19 & 1.16 & 1.22 \\
\hline 1963 & 0.75 & 0.73 & 0.77 & 0.99 & 0.94 & 1.04 & 1988 & 0.92 & 0.90 & 0.93 & 1.18 & 1.15 & 1.21 \\
\hline 1964 & 0.74 & 0.72 & 0.76 & 0.99 & 0.95 & 1.05 & 1989 & 0.92 & 0.90 & 0.93 & 1.19 & 1.16 & 1.22 \\
\hline 1965 & 0.74 & 0.72 & 0.76 & 1.02 & 0.97 & 1.07 & 1990 & 0.92 & 0.90 & 0.93 & 1.22 & 1.19 & 1.25 \\
\hline 1966 & 0.75 & 0.73 & 0.77 & 1.03 & 0.99 & 1.08 & 1991 & 0.93 & 0.91 & 0.94 & 1.19 & 1.16 & 1.22 \\
\hline 1967 & 0.75 & 0.73 & 0.77 & 1.05 & 1.00 & 1.10 & 1992 & 0.94 & 0.93 & 0.95 & 1.19 & 1.16 & 1.22 \\
\hline 1968 & 0.77 & 0.75 & 0.79 & 1.02 & 0.97 & 1.06 & 1993 & 0.93 & 0.92 & 0.95 & 1.21 & 1.18 & 1.24 \\
\hline 1969 & 0.79 & 0.77 & 0.81 & 1.05 & 1.01 & 1.10 & 1994 & 0.94 & 0.92 & 0.95 & 1.23 & 1.20 & 1.26 \\
\hline 1970 & 0.79 & 0.77 & 0.81 & 1.07 & 1.03 & 1.12 & 1995 & 0.94 & 0.93 & 0.96 & 1.21 & 1.18 & 1.24 \\
\hline 1971 & 0.81 & 0.79 & 0.83 & 1.09 & 1.04 & 1.13 & 1996 & 0.94 & 0.93 & 0.95 & 1.22 & 1.19 & 1.25 \\
\hline 1972 & 0.80 & 0.78 & 0.82 & 1.05 & 1.01 & 1.09 & 1997 & 0.96 & 0.95 & 0.98 & 1.25 & 1.22 & 1.28 \\
\hline 1973 & 0.83 & 0.81 & 0.85 & 1.07 & 1.03 & 1.11 & 1998 & 0.98 & 0.97 & 1.00 & 1.21 & 1.18 & 1.24 \\
\hline 1974 & 0.81 & 0.79 & 0.82 & 1.11 & 1.07 & 1.15 & 1999-2002 & 1.00 & 0.99 & 1.00 & 1.16 & 1.15 & 1.18 \\
\hline 1975 & 0.84 & 0.82 & 0.85 & 1.06 & 1.02 & 1.10 & 2003-2007 & 1.05 & 1.04 & 1.06 & 1.20 & 1.18 & 1.21 \\
\hline
\end{tabular}

Poisson regression models were fitted for each calendar year or time period and included such covariates as age, sex, socioeconomic deprivation quintiles, and metropolitan-nonmetropolitan residence

adults aged $\geq 20$ years was $37.8 \%$ for persons living in central cities of metropolitan areas, $36.5 \%$ for persons living outside the central cities in metropolitan areas, $36.5 \%$ for persons living in nonfarm residences outside metropolitan areas, and $25.1 \%$ for persons living on farms [20]. Contemporary NHIS data indicate changing ruralurban patterns in smoking prevalence, with smoking rates being currently higher among men and women in nonmetropolitan areas than in metropolitan areas and smoking prevalence increasing in relation to increasing levels of rurality [6, 7]. In 2008, for example, current smoking prevalence was $18.1 \%$ in large metropolitan areas, $21.7 \%$ in small metropolitan areas, and $26.1 \%$ in non-metropolitan areas [7]. Besides current smoking rates, metropolitannonmetropolitan disparities in lung cancer mortality may also reflect rural-urban differences in tobacco regulation and advertising, availability of cigarettes, and public awareness of the harmful health effects of smoking [5, 21]. In 2006-2007, for example, $80.6 \%$ of adults in metropolitan areas reported home smoking bans, compared to $71.4 \%$ of adults in nonmetropolitan areas [21].

Although we used the broad metropolitan-nonmetropolitan classification to analyze long-term trends, it is important to note that, within each broad category, lung cancer mortality rates do vary according to urbanization levels. Based on our analysis (not shown here), lung cancer mortality rates currently increase with increasing levels of rurality or decreasing levels of urbanization. For example, within the broader metropolitan category, men in medium and small metropolitan counties in 2007 had 12 and 19\% higher lung cancer mortality than men in large metropolitan counties, respectively. Thus, a shorter time-trend or cross-sectional analysis of urbanization patterns in mortality may benefit from using a more detailed rural-urban continuum variable. 
Lung cancer continues to be a leading cause of cancer death in the industrialized world, and cross-national comparisons of lung cancer mortality patterns can highlight important rural-urban differences as well as similarities in socioeconomic conditions, mortality risks, and smoking prevalence among countries [22]. Our study is consistent with a UK study that found significantly higher lung cancer mortality rates in rural areas than in urban areas of England during the period 2002-2004 before and after adjustment for deprivation [23]. Excess lung cancer mortality in rural areas was also found in a recent analysis for Australia covering the period 1997-1999 [24]. Compared to the rates in urban areas, lung cancer mortality rates during the period 1986-1996 were generally lower for Canadian men and women in rural areas [24]. The Canadian pattern is generally consistent with the US pattern if we compare rural-urban disparities for the two countries for a similar time period. Rural-urban patterns in lung cancer mortality are not known for Canada for a more recent time period. In many European countries (such as Denmark, Spain, Germany, and Italy) that have relatively high lung cancer mortality rates, smoking prevalence tends to be higher in urban than in rural areas, which may imply significantly higher lung cancer mortality risks among their urban residents [25].

The extent of metropolitan and non-metropolitan disparities in lung cancer mortality documented here has a substantial impact on the overall cancer disparities in the United States, since lung cancer is the leading cause of cancer mortality [1,2]. Given the continuing disparities in smoking prevalence, rural-urban disparities in lung cancer mortality are expected to widen in the future. Currently, men and women in both metropolitan and non-metropoli$\tan$ areas of the United States have a higher smoking prevalence than the Healthy People 2010 goal of $12 \%$ [26]. Health policy interventions (e.g., smoking prevention and tobacco control programs) aimed at reducing lung cancer disparities should continue to target those in rural and medically underserved areas.

Acknowledgments None. The views expressed are the authors' and not necessarily those of the Health Resources \& Services Administration or the US Department of Health \& Human Services.

\section{Conflicts of interest None.}

Open Access This article is distributed under the terms of the Creative Commons Attribution Noncommercial License which permits any noncommercial use, distribution, and reproduction in any medium, provided the original author(s) and source are credited.

\section{References}

1. Singh, G. K., Miller, B. A., \& Hankey, B. F. (2002). Changing area socioeconomic patterns in U.S. cancer mortality, 1950-1998: Part
II-lung and colorectal cancers. Journal of the National Cancer Institute, 94(12), 916-925.

2. Xu, J. Q., Kochanek, K. D., Murphy, S. L., \& Tejada-Vera, B. (2010). Deaths: Final data for 2007. National Vital Statistics Reports, 58(19), 1-136.

3. Howlader, N., Noone, A. M., Krapcho, M., et al. (Eds). (2011). SEER Cancer statistics review, 1975-2008. Bethesda, MD: National Cancer Institute; http://seer.cancer.gov/csr/1975_2008/.

4. National Center for Health Statistics. (2011). Health, United States, 2010 with special feature on death and dying. Hyattsville, MD: US Department of Health and Human Services.

5. Singh, G. K, Miller, B. A, Hankey, B. F, \& Edwards, B. K. (2003) Area socioeconomic variations in U.S. cancer incidence, mortality, stage, treatment, and survival, 1975-1999. NCI cancer surveillance monograph series, no. 4. Bethesda, MD: National Cancer Institute; NIH publ no. 03-5417.

6. National Center for Health Statistics. (2001). Health, United States, 2001 with urban and rural health chartbook. Hyattsville, MD: US Department of Health and Human Services.

7. Pleis, J. R., Lucas, J. W., \& Ward, B. W. (2009). Summary health statistics for U.S. adults: National health interview survey, 2008. Vital and Health Statistics, 10(242), 1-157.

8. National Center for Health Statistics. (2011). National vital statistics system, mortality multiple cause-of-death public use data file documentation. Hyattsville, MD: US Department of Health and Human Services. Available at: http://www.cdc.gov/nchs/ nvss/mortality_public_use_data.htm. Accessed May 17, 2011.

9. Butler, M. A., \& Beale, C. L. (1994). Rural-Urban continuum codes for metro and nonmetro counties, 1993. Washington, DC: Economic Research Service, US Department of Agriculture. Staff report 9425 .

10. Bureau of Health Professions. (2010). Area Resource File, 2009-2010, Technical documentation. Rockville, MD: Health Resources and Services Administration.

11. Singh, G. K., \& Siahpush, M. (2002). Increasing rural-urban gradients in US suicide mortality, 1970-1997. American Journal of Public Health, 92(7), 1161-1167.

12. Singh, G. K. (2011). Rural-urban trends and patterns in cervical cancer mortality, incidence, stage, and survival in the United States, 1950-2008. Journal of Community Health. [Epub ahead of print]. doi:10.1007/s10900-011-9439-6.

13. US Census Bureau. (2003). 2000 census of population and housing, summary file 3, technical documentation. Washington, DC: US Department of Commerce.

14. Singh, G. K. (2003). Area deprivation and widening inequalities in US mortality, 1969-1998. American Journal of Public Health, 93(7), 1137-1143.

15. Singh, G. K., \& Kogan, M. D. (2007). Widening socioeconomic disparities in US childhood mortality, 1969-2000. American Journal of Public Health, 97(9), 1658-1665.

16. Singh, G. K., \& Siahpush, M. (2006). Widening socioeconomic inequalities in US life expectancy, 1980-2000. International Journal of Epidemiology, 35(4), 969-979.

17. Singh, G. K., Miller, B. A., Hankey, B. F., Feuer, E. J., \& Pickle, L. W. (2002). Changing area socioeconomic patterns in U.S. cancer mortality, 1950-1998: Part I-all cancers among men. Journal of the National Cancer Institute, 94(12), 904-915.

18. Singh, G. K., \& Siahpush, M. (2002). Increasing inequalities in all-cause and cardiovascular mortality among US adults aged 25-64 years by area socioeconomic status, 1969-1998. International Journal of Epidemiology, 31, 600-613.

19. SAS Institute. (2004). SAS/STAT user's guide, version 9.1: The GENMOD procedure. Cary, NC: SAS Institute.

20. National Center for Health Statistics. The national health interview survey, questionnaires, datasets, and related documentation: 1976 Public use data file. Hyattsville, MD: US Department 
of Health and Human Services; 2009. Available at: http://www. cdc.gov/nchs/nhis/quest_data_related_1996_prior.htm. Accessed May 17, 2011.

21. US Census Bureau. (2008). Tobacco use supplement to the 20062007 current population survey: The public use data file and technical documentation. Sponsored by the National Cancer Institute and the Centers for Disease Control and Prevention. Washington, DC. Available at http://riskfactor.cancer.gov/ studies/tus-cps/. Accessed May 17, 2011.

22. Ferlay, J., Shin, H. R., Bray, F., Forman, D., Mathers, C., \& Parkin, D. M. (2010). GLOBOCAN 2008, cancer incidence and mortality worldwide: IARC cancer base no. 10 [Internet]. Lyon, France: International Agency for Research on Cancer. Available at: http://globocan.iarc.fr. Accessed June 22, 2011.

23. Gartner, A., Farewell, D., Roach, P., \& Dunstan, F. (2011). Rural/ urban mortality differences in England and Wales and the effect of deprivation adjustment. Social Science and Medicine, 72(10), $1685-1694$.

24. Legace, C., Desmeules, M., Pong, R. W., \& Heng, D. (2007). Non-communicable disease and injury-related mortality in rural and urban places of residence. Canadian Journal of Public Health, 98(Suppl 1), S62-S69.

25. Idris, B. I., Giskes, K., Borrell, C., Benach, J., Costa, G., Federico, B., et al. (2007). Higher smoking prevalence in urban compared to non-urban areas: Time trends in six European countries. Health Place, 13(3), 702-712.

26. US Department of Health, Human Services. (2006). Healthy people 2010: Midcourse review. Washington, DC: US Government Printing Office. 